\title{
The Establishment and Practice of Electrical and Electronic course Group
}

\author{
Qi Li ${ }^{1, c}$, Jingjing Yang ${ }^{1, b}$, Yanfei Liu ${ }^{1, a}$ and Yuan Zhao ${ }^{1, b}$ \\ ${ }^{1}$ Xi'an Research Institute of High Technology, Xi'an 710025, China; \\ abbmcu@126.com, byangjingjing8405@sina.com, 'Liqiqimail@126.com
}

Keywords: CDIO; Micro-lecture; Military Academy; teaching reform

\begin{abstract}
On the basis of the analysis of the present situation of school teaching, under the guidance of the basic ideas of CDIO Engineering Education Reform , and in line with the principle of outstanding the students' practical application ability, this paper proposed the establishment of electrical and electronic courses group. It optimized the teaching content, enriched teaching methods such as the project driven teaching method, tried the integrated teaching mode of theory, experiment and practice. The courses group not only raises the students' creative ability and practical ability, but also improves the teaching effect of the electrical and electronic courses, deepen the idea of CDIO Engineering Education.
\end{abstract}

\section{CDIO and the present situation of teaching}

The so-called CDIO is the latest achievements of international engineering education reform in recent years. It is the results that Massachusetts Institute of Technology and the Royal Institute of Technology and other four universities spent four years to get. CDIO stands for conceiving, designing, implementing and operating[1].It takes the life cycle of product research and development as the carrier. It lets the students learn actively, practically[2].

The goal is to cultivate the students' ability of the theory, personal quality and development ability, team cooperation ability and Engineering - social system adaptation and regulatory capacity. CDIO emphasis on strengthening the basic education and practical links for students at the same time. It could improve students' innovative ability and practical ability[3].

On the contradictions that technology development is faster and update speed of teaching content is lower, decreased curriculum hours and increased amount of information are existed in the local universities. Through the research we found that the teaching effect of "the basis of circuit analysis "," analog electronic technology "," digital electronic technology "and other electrical and electronic courses is not ideal. Students need to learn much of the electronic technology after graduation. And this kind of courses has the feature of strong engineering, so students need to pay attention to both theory and practice.

But there is no engineering background in the traditional theory of learning. Problems which encountered in the experimental operation can't dock with the theory of knowledge. This made the students have a strong dependence on experiment. Students' capacity of independent operation and independent design is weak. The cause of the problem is the theory, experiment and practice of curriculum reformed in conflicts, lacking of unified planning and system design. Therefore, how to combine the theory teaching, experiment and practice of electrical and electronic courses organically to improve the students' comprehensive quality is one of the problems that need to be studied and solved at present.

On the basis of analysis of the present situation of school teaching, under the guidance of the basic ideas of CDIO Engineering Education Reform , and in line with the principle of outstanding the students' practical application ability, this paper proposed the establishment of electrical and electronic courses group. In this way, we can further optimize the teaching content, enrich teaching methods, try the integrated teaching mode of theory, experiment and practice teaching mode, cultivate students' ability to analyze and solve problems and improve the teaching effect of electrical and electronic courses[4]. 


\section{The establishment and implementation of electrical and electronic course group}

The basic idea of CDIO Engineering Education reform is to take the knowledge, ability and quality that he modern industry product, process or system development of modern engineers need as the goal, to take the modern engineering as the background, to train students with the curriculum system of mutual connection and mutual support. Students could obtain experiences of design, development and active learning in the practical environment[5]. This promotes the integration of students' knowledge, ability and quality.

2.1 Breaking the boundaries of theory, experiment and practice, and unified planning the content system of "electrical and electronic course group"

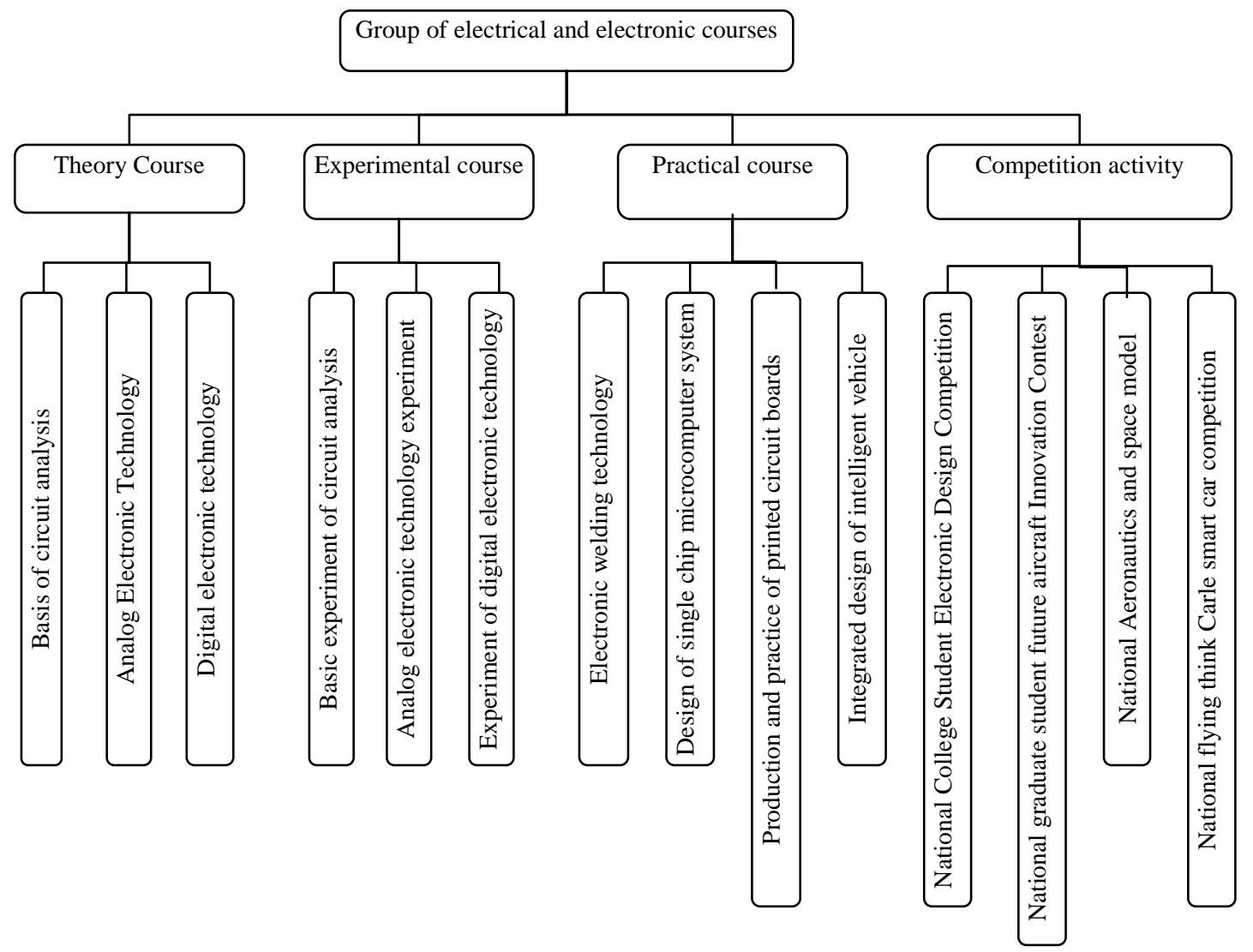

Fig. 1 "four in one" group of Electrical Engineering and Electronic System

Combined with the basic idea of CDIO Engineering Education and specific requirements of Electrical Engineering and Electronic group that our school professional training program requested, a scientific curriculum system which consisted of three theoretical courses, three experimental courses and six practical courses was established. Playing the advantages of relating group courses and complementary, a new "four in one" group of Electrical Engineering and Electronic System which was set up. This could highlight the basic theory and engineering practice integration, train students' ability of self-learning, engineering and innovative design[6].

According to the new system construction team, all-round development of the construction of teaching resources, to promote the new textbooks compiled and published, optimizes the multimedia teaching courseware is designed, which is suitable for remote teaching the course website, development of innovative experiment project, innovative teaching mode and teaching methods, and constantly promote the implementation and perfection of the new curriculum teaching system, in order to lay the foundation for the further upgrading of the teaching quality and level.

2.2 Research project of the traction type experimental teaching method, the establishment of engineering practice characteristics of the new model of experimental teaching

Integration of military background electrical courses groups the experimental course, basic course of electronic design experiment plan practice teaching content design, increase the comprehensive 
and design experiments[7]. The knowledge points which are nested under the comprehensive program are splitted in turn. They are formed as discrete tasks to enable students to master knowledge in a single course. So that relationship between discrete tasks becomes the bridge and link between the Electric \& Electronic Course groups.

Actively carrying out extra-curricular activities in science and technology, organization "our cup" science and technology innovation contest, guiding the students to attend in Shaanxi Province and the national electronic design competition, mechanical innovation design competition and HM national bidding competition and other high level competition, competition to promote learning, to promote the construction season, fully realize the combination of theory and actual.

The practice of teachers as the leading to the students as the main body, optional experimental subjects, optional experimental equipment, independent innovation experimental teaching mode, to stimulate students to learn the vitality and creativity[8].

\subsection{Project driven teaching method based on integration of theory and Practice}

In view of the present situation of the electrical and electronic courses, teaching content and the actual electronic systems are closely connected, select a relatively complete and systematic knowledge module project driven teaching method to try, to enable students to experience the complete circuit analysis, design, simulation, plate making, welding and debugging process, realize the theory teaching and practice teaching of the seamless connection, solve the problem of the disconnection between theory teaching and practice.

Through the Project driven teaching method to the project for traction, by teachers with the specific teaching content arrangement related to the electronic system design project, students independently complete the project design and simulation, by the teacher evaluation scheme and feasibility. In the laboratory complete circuit of the welding and debugging, and by the teacher evaluation project implementation results[9].

Thus under the guidance of teachers, the more control over the learning process is handed over to the students, allowing students to form their own mission objectives, to mobilize their knowledge, putting forward their own doubts, to guide their exploration of the process of self-monitoring, training students' self-construction of knowledge, to enhance students' ability of post office, and also can effectively improve students' engineering practice and innovation ability.

\subsection{The establishment of integrated curriculum evaluation system}

Most of the long-term since the electrical and electronic courses examination content is the basic theoretical knowledge in the textbooks, and not some relevant knowledge embodied in the course system of integration and engineering practice ability assessment.

Usually the objective questions and subjective analysis questions are less; the theory test, application testing less. The lack of comprehensive investigation on the students' knowledge, ability and engineering quality, the result is lead to student examination before much rote learning, analysis and induction of the less, is not conducive to the comprehensive analysis ability of students in the cultivation of innovative thinking and the formation of, is not conducive to engineering practice ability raise.

On the basis of the concept of CDIO, an integrated assessment system was builded. First, the diversity of assessment methods. On the basis of inheriting the traditional assessment methods, draw lessons from domestic and international advanced examination methods, such as small papers, writing reports and defense, physical testing and production, extracurricular science and technology competitions, and other examination methods. Second, the comprehensive assessment of content. On the basis of analyzing the methods focus on the understanding of the basic concepts, basic circuit, pay more attention to students' practical ability evaluation. The evaluation of the reform is conducive to a more comprehensive and objective assessment of the students' studies and assessment of student achievement, but also to guide the students to focus on the flexible use of knowledge and comprehensive ability, the overall quality of the training, to cultivate students' engineering practice ability and innovative ability has obvious effect[10].

In accordance with the above teaching practice, can better stimulate the enthusiasm of students learning and cultivate interest, improve their practical ability, cultivate the sense of innovation, so as 
to learn subsequent courses and lay a solid electrical knowledge and basic skills, to achieve training objectives.

\section{Conclusion}

Through the above initiatives, electrical and electronic group courses teaching can truly accomplish the essence of the concept of CDIO - learning by doing and learning based on project. It could truly implement the objectives of the training program for College Teachers on Innovative Consciousness and Application Ability. The organic between theory, experiment and practice teaching of electrical and electronic group courses was realized.

Through the integration of theory and practice of project-driven teaching, cultivate the students' ability of analyzing, designing, welding and debugging actual electronic system. This could provide students with knowledge and ability reserve to follow the relevant courses of study and participate in various academic competitions and other practical Competition. It achieved the excellent engineer training requirements.

\section{References}

[1]. Xu Liang, Chen Yunda. Teaching design and implementation of "doing middle school" curriculum based on CDIO -- a case study of the course of construction and operation of cable telephone network [J]. Journal of Tianjin Vocational Institute,2010(6). (In Chinese)

[2]. Huang Yaping, Chen Xiaoyuan, Zhang Yongliang. The teaching reform of "database principle and application" course based on CDIO model [J].Conference on Creative Education,2011. (In Chinese)

[3]. Yang Qirao,Cheng Sen,Wu Hao. Teaching reform and practice of electronic technology course based on CDIO concept [J]. Journal of Zhejiang Institute of water conservancy and hydroelectric power,2014(3). (In Chinese)

[4]. Guo Yu,Li Duan,Wang Xiaodan. Project oriented "three" basic course of multidimensional assessment system research and Practice [J]. Heilongjiang Education (higher education research and evaluation),2014(6). (In Chinese)

[5]. Cai Zhi,Zhang Xuejin. Teaching reform of software engineering course group based on CDIO model [J].2010Third International Conference on Education Technology and Training,2010. (In Chinese)

[6]. Cao Haiping,Guan Tuhua. Refrom and Practice of electrical and electronic practice teaching based on CDIO concept [J].Research and Exploration in Laboratory,2013(1). (In Chinese)

[7]. Zhong Shouxian,Zhang Ying,Guo Shaohui. Exploration and practice of the teaching mode of mpc-cdio Education [J].Research on Higher Engineering Education,2015(2). (In Chinese)

[8]. Hu Wenlong. Research on the teaching reform of Engineering inquiry based on CDIO [J]. Research on Higher Engineering Education,2014(1). (In Chinese)

[9]. Zhou Yuan,Mai Yunfei. Research on teaching mode of mechatronics system design course based on CDIO [J].The Science Education Article Collects,2015(2). (In Chinese)

[10]. Huang Yishen,DongChenchen,Wen Xiaohong,Pan Posong.Exploration on the construction of CDIO practice platform for the cultivation of excellent engineers[J].Journal of Zhejiang University of Technology(Social Science Edition),2013(12). (In Chinese) 